\section{Diluted porcine surfactant lung lavages in children with severe ARDS}

\author{
LUCA TORTOROLO • ANTONIO CHIARETTI • SILVIA PULITANÒ • \\ ORAZIO GENOVESE • GIORGIO CONTI
}

\author{
LUCA TORTOROLO $(\triangle) \bullet$ \\ ANTONIO CHIARETTI • \\ SILVIA PULITANÒ • \\ ORAZIO GENOVESE • \\ GIORGIO CONTI \\ Pediatric Intensive Care Unit \\ Emergency Department A. Gemelli \\ Hospital of Rome \\ Via A. Caroncini 27. \\ 00197 Roma, Italy \\ Phone: +39 360601422 \\ Fax: +39630155283 \\ E-mail: 360601422@tim.it
}

\begin{abstract}
Acute respiratory distress syndrome (ARDS) is characterized by damage to the arteriolar-capillary endothelium and alveolar epithelium that leads to surfactant deficiency and atelectasis. Alveolar collapse and pulmonary edema will further induce surfactant inactivation. Surfactant supplementation has been suggested but results are unpredictable. Poor response may be due to inhibition of administered surfactant by plasma components filling the alveolar space, severity of lung injury, time of surfactant application and inadequate dose. We report the course of gas exchange and pulmonary mechanics after instiIlation of surfactant in 14 children (3 months-7 years) with severe ARDS, defined as an oxygenation index (OI) $>30$ and a partial pressure of oxygen/ fraction of Inspired oxygen $\left(\mathrm{PaO}_{2} / \mathrm{FiO}_{2}\right)<150$. We used a diluted concentration of Curosurf (8 $\mathrm{mg} / \mathrm{ml}$ ) divided into 4 aliquots, for a total dose of $25 \mathrm{mg} / \mathrm{kg}$. An additional aliquot was used for bronchoalveolar lavage before surfactant treatment.

All children showed a dramatic response to surfactant with rapid and progressive increase in compliance and improvement of all respiratory mechanics. Mechanical ventilation settings were rapidly reduced and gas exchange improved with a $\mathrm{PaO}_{2} / \mathrm{FiO}_{2}>200$ for more than 12 hours.

Diluted surfactant lung lavages were able to increase blood gas exchange in all our patients despite previously severe gas exchange impairment.
\end{abstract}

Keywords: ARDS, pulmonary surfactant, bronchoalveolar lavages, child

\section{Introduction}

Acute respiratory distress syndrome (ARDS) is a lung pathology induced by diverse injuries, including trauma, sepsis, liquid aspiration, inhaled gases, radiation, pneumonitis and many others.

Despite the introduction of new treatments, the mortality from ARDS in the pediatric age group remains high (about 40\%). (1) ARDS is characterized by damage to the arteriolar-capillary endothelium and alveolar epithelium, including type I and type II pneumo- cytes. (2) Damage to the latter results in surfactant deficiency and atelectasis. Even though surfactant abnormalities in ARDS are not the primary pathogenic factor, surfactant deficiency, either in the presence or absence of type II pneumocyte alterations, may result from primary or secondary inhibition or inactivation of pulmonary surfactant in the alveolar space. $(2,3)$ Surfactant deficiency and inactivation will further induce alveolar collapse and pulmonary edema, leading to the characteristic pathophysiology of ARDS. (2,3)

Surfactant supplementation has been suggested but the treatment is unpredictable. $(4,5)$ Poor response may be due to inhibition of administered surfactant by plasma components filling the alveolar space related to the severity of lung injury. Therefore, the timing and modality of surfactant application seems very important. (3-5)

In our study we report the course of gas exchange and pulmonary mechanics in 15 children with severe ARDS treated with repeated bronchoalveolar lavages of diluted natural porcine surfactant (Curosurf).

\section{Material and methods}

We enrolled all children admitted between January 2005 and December 2007 to the Pediatric Intensive Care 
Units of A. Gemelli University Hospital and Bambino Gesù Hospital of Rome with severe ARDS, defined as an $\mathrm{OI}>$ 20 and $\mathrm{a} \mathrm{PaO}_{2} / \mathrm{FiO}_{2}<150$ in patients who required more than $12 \mathrm{cmH}_{2} \mathrm{O}$ of mean alveolar pressure under mechanical ventilation. Children with chronic lung diseases and major cardiac malformations were excluded. This group of children with severe ARDS was treated with tracheobroncoalveolar lavage using a 10 times diluted concentration of Curosurf $(8 \mathrm{mg} / \mathrm{ml})$. Lavage was performed with an instilled volume of $3 \mathrm{~mL} / \mathrm{kg}$ of diluted surfactant repeated 3 times for a total surfactant dose of $24 \mathrm{mg} / \mathrm{kg}$. After 5 hand bagging maneuvers, to distribute the solution well, deep suction of the airways was applied. A corrected procedure was defined as one which reached a recovery volume of more than $40 \%$. As soon as the child's cardiorespiratory parameters were stabilized, we instilled the same diluted surfactant solution used for the lavages through a catheter inserted in the endotracheal tube and placed the infants in 4 classical decubitus positions. Suctioning was avoided for the subsequent 2 hours. Gas exchange was monitored continuously via oxygen saturation, end tidal $\mathrm{CO}_{2}$ and a transcutaneous monitor. Heart rate, blood pressure, central venous pressure and urine output were also recorded. Monitoring of all cardiorespiratory parameters was continuously performed during the whole procedure and ventilator setting was adjusted to keep $\mathrm{SO}_{2}>92 \%$ and end -tidal $\mathrm{CO}_{2}$ in the range between $40-50 \mathrm{mmHg}$. Pulmonary function tests were performed before, and $30 \mathrm{~min}, 1 \mathrm{hr}, 4 \mathrm{hr}, 8 \mathrm{hr}, 12 \mathrm{hr}$, $24 \mathrm{hr}, 48 \mathrm{hr}$ and $72 \mathrm{hr}$ after treatment.

\section{Results}

The sample consists of fourteen $(n=14)$ children. The age of our children ranged between 3 months and 7 years, and the origin of ARDS was very different: burn, septic shock, bronchiolitis, pulmonary thromboembolism, trauma and pleuropneumonia (table 1). Pediatric risk of mortality (PRISM) score ranged between 10 and 13 points (table

Table 1. General clinical characteristics of studied children.

\begin{tabular}{|c|c|c|c|c|c|}
\hline $\begin{array}{l}\text { GENERAL CLINICAL } \\
\text { CHARACTERISTICS }\end{array}$ & Age & Gender & ARDS etiology & PRISM & Ol \\
\hline 1 & $5 \mathrm{yr}$ & $\mathrm{F}$ & Burn & 13 & 36 \\
\hline 2 & $1 \mathrm{yr}$ & $\mathrm{F}$ & Sepsis & 12 & 33 \\
\hline 3 & $4 \mathrm{mo}$ & M & Bronchiolitis & 10 & 30 \\
\hline 4 & $6 \mathrm{mo}$ & M & Pneumonia & 11 & 30 \\
\hline 5 & $2 y r$ & $M$ & DIC, Meningitis & 13 & 31 \\
\hline 6 & $6 y r$ & $\mathrm{~F}$ & $\begin{array}{l}\text { Disseminated } \\
\text { TBC }\end{array}$ & 12 & 31 \\
\hline 7 & $3 y r$ & $M$ & Tonsillectomy & 13 & 32 \\
\hline 8 & $4 \mathrm{yr}$ & M & $\begin{array}{l}\text { Aspiration } \\
\text { pneumonia }\end{array}$ & 13 & 33 \\
\hline 9 & $5 \mathrm{mo}$ & M & Bronchiolitis & 10 & 30 \\
\hline 10 & $3 \mathrm{mo}$ & $\mathrm{F}$ & Bronchiolitis & 11 & 30 \\
\hline 11 & $4 \mathrm{yr}$ & M & Pneumonia & 11 & 31 \\
\hline 12 & $10 \mathrm{mo}$ & $\mathrm{F}$ & $\begin{array}{l}\text { Aspiration } \\
\text { pneumonia }\end{array}$ & 13 & 34 \\
\hline 13 & $3 \mathrm{mo}$ & M & Bronchiolitis & 12 & 32 \\
\hline 14 & $7 y r$ & $\mathrm{~F}$ & Trauma & 10 & 30 \\
\hline
\end{tabular}

ARDS, acute respiratory distress syndrome; DIC, disseminated intravascular coagulation; $F$, female; M, male; mo, months; OI, oxygenation index; PRISM, Pediatric Risk of Mortality; TBC, tuberculosis; yr, years.

1). Mechanical ventilation was set in order to reduce baro and volutrauma using small tidal volume, high respiratory rate, permissive hypercapnia and prone position. Two children were under high frequency oscillation ventilation (HFOV). All patients were receiving corticosteroid treatment.

Every child showed a dramatic response to surfactant with rapid and progressive increase in compliance from a mean of 0.43 (range 0.38-0.51) before surfactant treatment to 0.97 (range 0,85-1.2) $\mathrm{cmH}_{2} \mathrm{O} / \mathrm{ml} / \mathrm{kg} 12$ hours after treatment (figure 1). Mean Ol dropped under 15 (range 5-18) and mean $\mathrm{PaO}_{2} /$ $\mathrm{FiO}_{2}$ increased over 250 (range 216-
260) in less than 6 hours (figure 2). Mechanical ventilation set was rapidly reduced obtaining a mean (mean arterial pressure) MAP $<10 \mathrm{cmH}_{2} \mathrm{O}$ and this improvement in gas exchange was kept for more than 12 hours (figure 2). After that, all patients recorded progressive pulmonary deterioration characterized by an increase in oxygen supplementation. In 6 out of 14 children the $\mathrm{PaO}_{2} /$ $\mathrm{FiO}_{2}$ ratio returned to below 150 and we re-treated them with a new course of diluted surfactant. The response to the second dose was less impressive and more delayed, but in 48 hours all babies increased their $\mathrm{PaO}_{2} / \mathrm{FiO}_{2}$ over 250. All patients were extubated 


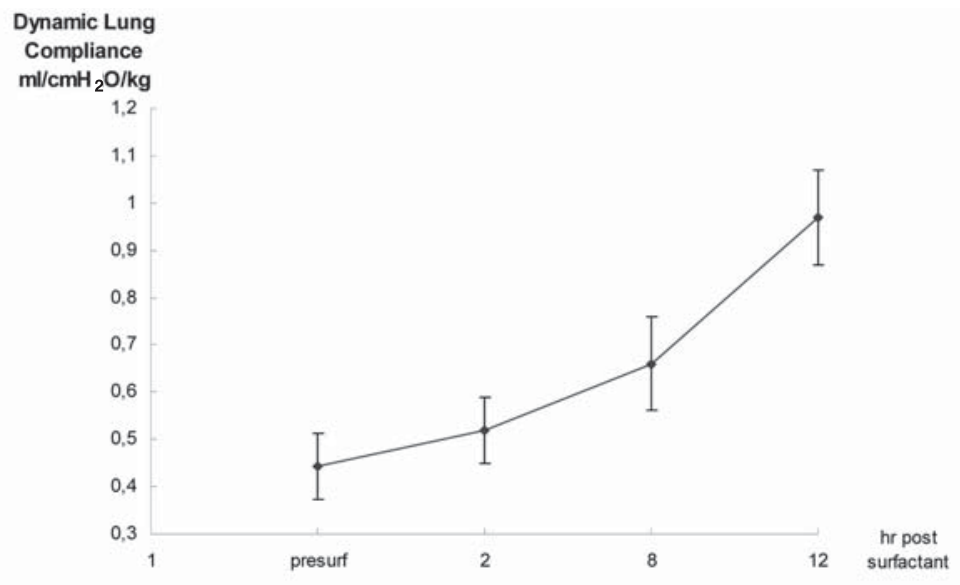

Dynamic respiratory compliance $\left(\mathrm{C}_{\mathrm{rsd}} \mathrm{dyn}\right)$ in the surfactant treated children

Figure 1. Lung compliance before and after treatment.

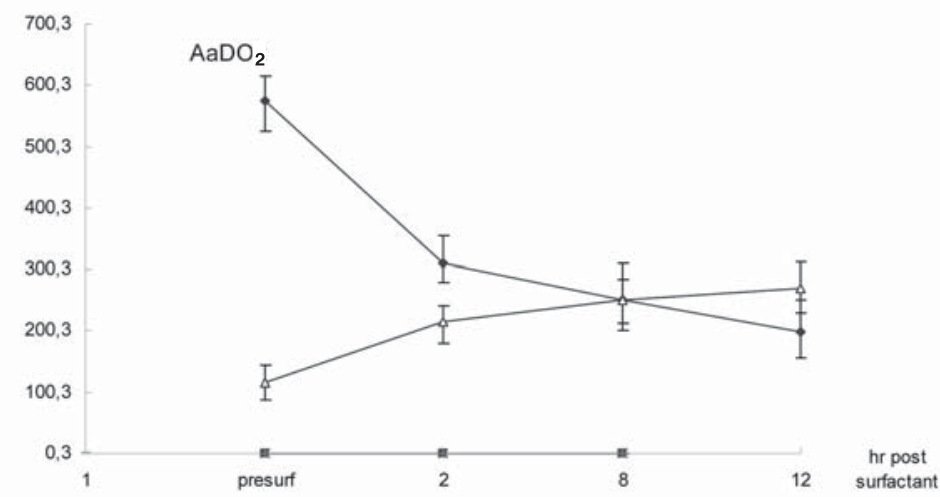

$\mathrm{AaDO}_{2}\left[760-47\left(-\mathrm{PaCO}_{2} \cdot \mathrm{PaO}_{2}\right) \times 100\right]$

and $\mathrm{PaO}_{2} / \mathrm{FiO}_{2}$ ratio in the surfactant treated children

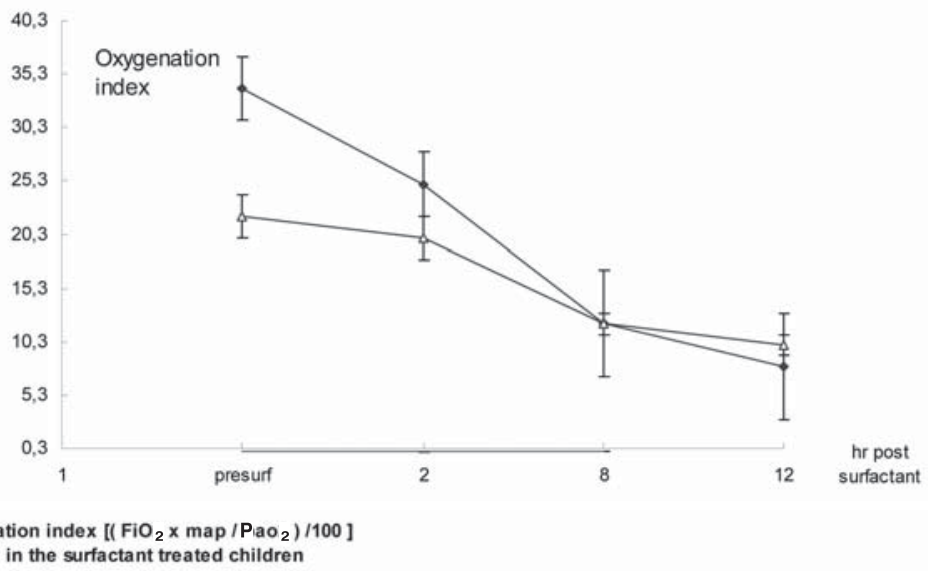

Oxygenation index $\left[\left(\mathrm{FiO}_{2} \times\right.\right.$ map $\left.\left./ \mathrm{PaO}_{2}\right) / 100\right]$
and MAP in the surfactant treated children

Figure 2. Gas exchange (mean $\pm \mathrm{sd}$ ) in treated children. and discharged from the intensive care unit (ICU) without major complications. Only 1 patient, who had severe tuberculosis pleuropneumonia and was under HFOV, developed a bilateral pneumothorax and pneumomediastinum in the first hours after surfactant treatment (which required surgical drainage).

\section{Discussion}

Diluted surfactant lung lavages were able to increase blood gas exchange in all our patients despite all of them suffering from severe ARDS with $\mathrm{Ol}>$ 30. This improvement was faster and more impressive right after the first than the second dose. Experimental animal data have shown strong evidence that tracheobronchial lavages with surfactant are extremely efficacious in the most severe forms of ARDS in which alveolar ventilation is extremely heterogenic and the majority of the alveoli are filled with edema proteins. (6-8) When regular instillation of exogenous surfactant is performed, this distribution is less homogenic and the small amount of surfactant that reaches the alveoli surface is rapidly inactivated by inflammatory and edema proteins. (6-8) This is one of the main reasons why the majority of randomized controlled trials on surfactant treatment in children with ARDS failed to find a beneficial effect. A recent meta-analysis pointed out that trials paid special attention to the selection of the population, type, dosage, timing and ways of administration of surfactant achieving a statistical significant effect in surfactant treated children in term of reduction of days of mechanical ventilation, days of ICU stay and one study also in mortality. (9) Despite the limitations of our study (we didn't have a control population), it demonstrates very clearly the improved distribution and efficacy of diluted surfactant using lung lavages. A larger, randomized controlled trial is needed to confirm this important finding. 


\section{REFERENCES}

1. Bush A. Up Date in pediatric lung disease 2008. Am J Respir Crit Care Med 2009;179:637-49.

2. Dahlem P, van Aalderen WM, Bos AP. Pediatric acute lung injury. Pediatric Respir Rev 2007;8:348-62.

3. Willson DF, Chess PR, Notter RH. Surfactant for pediatric acute lung injury. Pediatric Clin North Am 2008;55:545-75.

4. Marraro GA, Lucchetti M, Spada C, Galassini E, Giossi M, Piero AM. Selective medicated (normal saline and exogenous surfactant) bronchoalveolar lavage in severe aspiration syndrome in children. Pediatr Crit Care Med 2007;8:505-6.

5. Luchetti M, Ferrero F, Gallini C, Natale A, Pigna A, Tortorolo L, et al. Multicenter, randomized, controller study of porcine .surfactant in severe respiratory syncitial virus-induced respiratory failure. Pediatr Crit Care Med 2002;3:261-6.

6. Meister J, Venkataraman B, Ramirez M, Uyehara FT, Killeen J, Ku T, et al. Lavage administration of diluted surfactant in a piglet model of meconium aspiration. Lung 2004;182:227-40.

7. Gommers D, Eijking P, So Kl, van't Veen A, Lachmann B. Bronchoalveolar lavage with a diluted surfactant suspension prior to surfactant instillation improves the effectiveness of surfactant therapy in experimental acute respiratory distress syndrome (ARDS). Intensive Care Med 1998;24:494-500.

8. Cochrane G, Revak S. Surfactant lavage treatment in a model of respiratory distress syndrome. Chest 1999;116:85-6.

9. Duffett M, Choong K, Ng V, Randolph A, Cook DJ. Surfactant therapy for acute respiratory failure in children: a systematic review and meta-analysis. Crit Care 2007;11:66. 